\title{
$\angle S$ Research Square \\ The Prophylactic Effect of Silver Sulphadiazine and Chloroquine in-situ Gel Formulation Against Rodent Malaria Parasite Plasmodium Berghei
}

Noha Zelai ( $\square$ nzelai@kau.edu.sa )

King Abdulaziz University https://orcid.org/0000-0002-3353-9761

Original Article

Keywords: Malaria, chloroquine, silver sulphadiazine, in-situ gel, Plasmodium berghei, pharmacokinetic

Posted Date: February 4th, 2021

DOI: https://doi.org/10.21203/rs.3.rs-160777/v1

License: (9) This work is licensed under a Creative Commons Attribution 4.0 International License. Read Full License 


\section{Abstract}

Background: Despite the technological advances made in the pharmaceutical field, globally, malaria remains one of the major causes of mortality. The resistance of malaria parasites to conventional drugs is one of the primary challenges facing researchers. Therefore, the aim of this study is to examine the validity of a single dose in-situ gel formulation of chloroquine and silver sulfadiazine against rodent model malaria, Plasmodium berghei.

Results: Following administration of the free or gel drug formulations to mice four days before infection, the insitu gelled formulation were not found to improve drug parasitaemia nor increase the life span of the infected mice. This may be attributed to the initial high burst of drug release within the initial days of treatment before infection.

Conclusions: Additional studies are warranted to determine the timing of the malarial drug burst, and to design the prophylactic interval based on the drug pharmacokinetics and their metabolites.

\section{Background}

Malaria is a life-threatening disease caused by Plasmodium parasites and is transmitted by Anopheles mosquitoes. According to the WHO, in 2017 there were an estimated 219 million cases of malaria worldwide, with 435000 deaths (WHO, 2017). A person's overall health, as well as a community's degree of public awareness regarding the spread of malaria, significantly impact the rate of transmission. Specifically, immunocompromised individuals, pregnant women, and children with low immunity are more likely to become infected (Fontaine et al., 1961; Shankar, 2000; Craig et al., 2004; van Eijk et al., 2004). Meanwhile, public awareness regarding malaria diagnosis and treatment strategies has been reported to increase the number of individuals seeking medical treatment when suffering from long-term acute undifferentiated fever (Naing et al., 2017). Additionally, the growing number of malaria cases in non-endemic countries has been attributed to travel. Specifically, immigration or travel to sub-Saharan Africa, India, and Southeast Asia has led to an increased number of imported malaria cases (WHO, 2004, Jelinek et al., 2002, Spira, 2003). In fact, Denmark reported the number of imported cases to be as high as 714 per 100,000 among Ghana travelers, and 2.5 per 100,000 in individuals who had traveled to Thailand (Kofoed and Petersen, 2006). Moreover, global climate change significantly impacts the transmission of malaria as it allows the vector to inhabit new areas of the world. Hence, identifying effective therapeutic options capable of slowing the spread of malaria is urgently required in an effort to protect large populations of malaria-susceptible individual's within non-endemic regions of the world.

Development of effective prophylactic drugs is one strategy to slow the spread of malaria. Evidence suggests that in-situ gel containing drugs offer a more prolonged release compared to free drug formulations. Indeed, several studies have shown that in-situ gels have increased the drug efficacy against malaria with no histological side effects (Dawrea et al., 2011; Mahajan et al., 2018). In addition, our previous work showed that the cure rates of silver sulfadiazine and chloroquine phosphate in-situ gel formulations were $73 \%$ and $100 \%$, respectively, compared with $0 \%$ and $66.7 \%$ cure rates associated with the free drug formulas (Zelai, 2017). 
The aim of this study is to employ an in-situ gel as a carrier for two antimalarial drugs, chloroquine phosphate and silver sulfadiazine. The anti-Plasmodium berghei efficacy of the in-situ gel formulations was then compared to that of free drugs in vivo. In addition, the effect of these formulations on liver and kidney enzyme levels, as well as their associated pharmacokinetics, were examined.

\section{Results}

\subsection{Parasitaemia}

Mice received the drug formulations as prophylaxis four days before the injection of $P$. berghei. The results show no significant differences $(p=0.4159)$ in parasitemia between the different drug groups on day 3 (Fig. 1A). However, a lower level of parasitemia was observed in the free Cq-treated group compared to the Agsd in-situ gel $(p=0.0028)$, Cq in-situ gel $(p=0.0030)$, and control $(p=0.0005)$ groups on day 5 . Meanwhile, on day 7 , the Agsd-treated group had lower blood parasitemia than the control $(p=0.0422)$, while the free $\mathrm{Cq}$ treated group had lower parasitemia than both the $\mathrm{Cq}$ in-situ gel treated group $(p=0.0408)$ and the control group $(p=0.0026)$. No significant differences were observed among all groups on day $9(p=1654)$.

Surprisingly, mice administered free chloroquine and silver sulfadiazine had a lower level of parasitemia and a longer life span (Fig. 1B) compared to those administered in-situ gel formulations.

\subsection{Kidney and Liver function}

No significant differences were observed in creatinine or uric acid levels among all groups $(p=0.0702$ and 0.7787, respectively; Fig. 2A). Similarly, significant differences were not observed in alanine aminotransferase (ALT) or alkaline phosphatase ALKP levels between all groups $(p=0.0677$ and $p=0.3430$, respectively; Fig. 2B).

\subsection{Pharmacokinetic}

Agsd and its main active metabolite were tracked in mouse plasma. Results show that higher Agsd levels were detected on day 1 in the plasma of the in-situ gel mice compared to the free group (Fig. 3A). Meanwhile, the metabolite concentration was higher on day 5 in the free Agsd-treated group compared to the mice treated with the in-situ gel formulation; although these differences were not statistically significant $(p=0.5156$ and $p=$ 0.3506 for drugs and metabolites, respectively; Fig. 3B).

\section{Discussion}

In this work, the efficacy of silver sulfadiazine and chloroquine in-situ gel formulations were examined as prophylactic antimalarial drugs. These new formulations were assessed in mice to determine if they effectively reduce blood parasitemia and extend life span without negatively impacting liver or kidney enzymes. However, the in-situ gel formulations investigated in this study were found to have negative effects on $P$. berghei-infected mice.

Furthermore, in the free drug groups, lower levels of blood parasitemia and longer life spans were observed compared to in-situ gel groups. This may be attributed to the high burst of drugs released from the in-situ gel 
formulation shortly after administration, which would have occurred within the four-day period prior to infection. This postulation is supported by the pharmacokinetics of Agsd, which revealed a high burst of in-situ gel on day 1.

The poor efficacy of chloroquine in-situ gel may also be attributed to a high burst, but it may not be detected because chloroquine is known to be accumulated and distributed in tissues such as the liver and kidney, which causes elevation of some enzymes such as creatinine (El Shishtawy et al., 2015), as was seen in the in-situ gel Cq (Zelai, 2020).

Currently, there are limited studies available that report on in-situ gel-formulated drugs against malaria. One study demonstrated that a biodegradable in-situ gel polymer can be injected safely via intramuscular administration and offers an extended bioavailability for up to three days. In addition, treatment with arteetherlumefantrine-polymeric lyotropic liquid crystalline phase in-situ gel has been reported to cure mice of malaria infection and prolong their lifespan. However, the marketed arteether-treated group showed $100 \%$ mortality within 20 days (Dawrea et al., 2018). Another study found that pluronic and hydroxy propyl methyl cellulose insitu gel is stable for over 90 days under different temperatures and humidity conditions. Moreover, histopathological examination showed that this formulation is safe on the nasal mucosa of mice (Mahajan et al., 2011). Although other studies have shown that in-situ gel prolongs drug release (Mahajan et al., 2011, Dawrea et al., 2018), the current results demonstrate the opposite effect (Fig. 3). Hence, optimization of the insitu gel formulation should be performed to determine the most suitable formulation that will have a low initial burst followed by an extended release over more than eight days.

\section{Conclusions}

The formulation of 30\% PLGA (50:50) in N-Methyl-2-pyrrolidone NMP failed to prevent malaria infection. This drug formula has similar bioavailability and adverse effects in the liver and kidney, as those observed for free drugs. Future studies are recommended to examine the pharmacokinetics of in-situ gel formulations with different ratios of polymer, NMP, and drugs. Based on the pharmacokinetics PK results, new sets of mouse malaria infections can be carried out.

\section{Methods}

\subsection{Parasite}

Plasmodium berghei ANKA was obtained from Addis Ababa University, Ethiopia. The parasite was maintained by serial intraperitoneal injection into mice. The injection volume for all mice was $10^{6}$ parasitized erythrocytes in citrate saline.

\subsection{Mice}

Male and female Balb/c mice (weight 20-30 g) were obtained from the Animal House of the College of Pharmacy, King Saud University, Riyadh. The experiments were approved by the unit of Biomedical Ethics Research Committee, King Abdulaziz University, Saudi Arabia (Reference No 168 - 15; may 24, 2015). This study followed the ARRIVE guidelines. 


\subsection{Drugs}

Two drugs were used in this study: silver sulfadiazine (non-soluble in water) and chloroquine (soluble in water). Both drugs were received from Riyadh Pharma, Riyadh, Saudi Arabia.

\subsection{Preparation of free drugs}

The silver sulfadiazine free suspension was prepared by adding $50 \mathrm{mg}$ of the drug to $50 \mathrm{~mL}$ water, followed by sonication for 5-10 min and incubation overnight in a water bath shaker. Chloroquine $(50 \mathrm{mg})$ was dissolved in $1 \mathrm{~mL}$ of water with vertexing. The final volume was made to be $50 \mathrm{~mL}$ by adding water.

\subsection{Preparation of in-situ gel}

Silver sulfadiazine and chloroquine were dispersed in $30 \%$ poly (lactide-co-glycolide) 50:50 (CAS: 26780-50-7, molecular weight: $24-38 \mathrm{kDa}$ ) in N-methylpyrrolidone (NMP), as reported previously by $\mathrm{Yu}$ and Jagdish (Yu and Jagdish, 2008). The suspensions were then vortexed for $5 \mathrm{~min}$, placed in a $25^{\circ} \mathrm{C}$ water bath, and incubated with shaking for $24-72 \mathrm{~h}$.

\subsection{Mouse groups}

All mice received intramuscular prophylactic treatment 4 days before infection (Table $1, n=15$ in each group). The first two groups were treated with free silver sulfadiazine $(1.05 \mathrm{mg} / \mathrm{kg} / \mathrm{d}$ for 5 days) and free chloroquine phosphate (10 mg/kg/day). In-situ gel groups received one inoculum containing the total dose of the drug, $5.25 \mathrm{mg} / \mathrm{kg}$ silver sulfadiazine, and $40 \mathrm{mg} / \mathrm{kg}$ chloroquine phosphate. The control group received vehicle insitu gel for five days. Four days after treatment, all mice were infected with $10^{6}$ parasitized erythrocytes. Parasitemia was assessed via collection of mouse tail blood on days 3, 5, 7, and 9 post-infection, and life span was monitored for each mouse. 
Table 1

the experimental design of mouse experiments

\begin{tabular}{|c|c|c|c|c|c|c|}
\hline & Group 1 & Group 2 & Group 3 & Group 4 & Group 5 & $\begin{array}{l}\text { No. } \\
\text { of } \\
\text { mice }\end{array}$ \\
\hline Treatment & $\begin{array}{l}\text { Free silver } \\
\text { sulphadiazine }\end{array}$ & $\begin{array}{l}\text { Free } \\
\text { chloroquine } \\
\text { phosphate }\end{array}$ & $\begin{array}{l}\text { In-situ gel } \\
\text { silver } \\
\text { sulphadiazine }\end{array}$ & $\begin{array}{l}40 \mathrm{mg} / \mathrm{kg} \\
\text { chloroquine } \\
\text { phosphate }\end{array}$ & $\begin{array}{l}\text { Vehicle in- } \\
\text { situ gel }\end{array}$ & 15 \\
\hline Dose & $0.05 \mathrm{mg} / \mathrm{kg} / \mathrm{d}$ & $10 \mathrm{mg} / \mathrm{kg} / \mathrm{d}$ & $5.25 \mathrm{mg} / \mathrm{kg}$ & $40 \mathrm{mg} / \mathrm{kg}$ & $0.2 \mathrm{~mL}$ & \\
\hline Repetition & 5 days & 4 days & 1 day & 1 day & 5 days & \\
\hline Treatment route & i.m. & i.m. & i.m. & i.m. & i.m. & \\
\hline Infection & $\begin{array}{l}10^{6} \\
\text { parasitized } \\
\text { erythrocytes }\end{array}$ & $\begin{array}{l}10^{6} \\
\text { parasitized } \\
\text { erythrocytes }\end{array}$ & $\begin{array}{l}10^{6} \\
\text { parasitized } \\
\text { erythrocytes }\end{array}$ & $\begin{array}{l}10^{6} \\
\text { parasitized } \\
\text { erythrocytes }\end{array}$ & $\begin{array}{l}10^{6} \\
\text { parasitized } \\
\text { erythrocytes }\end{array}$ & \\
\hline Parasitemia & $\begin{array}{l}\text { Counted on } \\
\text { days } 3,5,7,9 \\
\text { post-infection }\end{array}$ & $\begin{array}{l}\text { Counted on } \\
\text { days } 3,5,7, \\
9 \text { post- } \\
\text { infection }\end{array}$ & $\begin{array}{l}\text { Counted on } \\
\text { days } 3,5,7,9 \\
\text { post-infection }\end{array}$ & $\begin{array}{l}\text { Counted on } \\
\text { days } 3,5,7, \\
9 \text { post- } \\
\text { infection }\end{array}$ & $\begin{array}{l}\text { Counted on } \\
\text { days } 3,5,7, \\
9 \text { post- } \\
\text { infection }\end{array}$ & \\
\hline Life span & Monitored & Monitored & Monitored & Monitored & Monitored & 15 \\
\hline $\begin{array}{l}\text { Liver and } \\
\text { kidneys enzyme }\end{array}$ & tested & $\begin{array}{l}\text { Tested in a } \\
\text { previous } \\
\text { work* }\end{array}$ & tested & $\begin{array}{l}\text { Tested in a } \\
\text { previous } \\
\text { work* }\end{array}$ & Tested & 3 \\
\hline Pharmacokinetic & tested & $\begin{array}{l}\text { Tested in a } \\
\text { previous } \\
\text { work* }\end{array}$ & tested & $\begin{array}{l}\text { Tested in a } \\
\text { previous } \\
\text { work* }\end{array}$ & tested & 3 \\
\hline
\end{tabular}

\subsection{Liver and kidney enzyme analysis}

Urea, creatinine, and uric acid, as well as aspartate aminotransferase (AST), alanine aminotransferase (ALT), and alkaline phosphatase (ALP) levels in blood plasma were measured using Vitros 350 (Johnson \& Johnson, USA).

\subsection{Pharmacokinetic analysis of drugs and their primary active metabolites}

Plasma samples $(250 \mu \mathrm{L})$ were spiked with serial silver sulfadiazine dilutions and its metabolite sulphamerazine which were used as standards for in vivo pharmacokinetic analysis. Plasma samples containing silver sulfadiazine were pre-treated to extract the drug from plasma after the addition of the internal standard $(62.5 \mu \mathrm{g} / \mathrm{mL})$.

Dilutions of $62.50,31.25,15.63,7.81,3.90$, and $1.95 \mu \mathrm{g} / \mathrm{mL}$ silver sulfadiazine and $\mathrm{N}$-acetyl sulfadiazine were prepared in mobile phase (1000:99:9, water:acetonitrile:phosphoric acid). In a separate tube, $62.5 \mu \mathrm{g} / \mathrm{mL}$ of 
sulfamerazine was prepared in mobile phase. Blank plasma $(250 \mu \mathrm{L})$ was spiked with different dilutions of 1:1 silver sulfadiazine and $\mathrm{N}$-acetyl sulfadiazine.

Nine plasma samples were collected from mice individually injected intramuscularly with a single dose of 50 $\mathrm{mg} / \mathrm{kg}$ silver sulfadiazine suspension or silver sulfadiazine nanocapsules. Samples were taken after $6,12,24$, and $48 \mathrm{~h}$. In addition, plasma was extracted from mice administered silver sulfadiazine suspensions or nanocapsules $(5.25 \mathrm{mg} / \mathrm{kg} / 5 \mathrm{~d})$ or silver sulfadiazine in-situ gel $(26.25 \mathrm{mg} / \mathrm{kg})$ by intramuscular injection. The time points were $6 \mathrm{~h}$ after the first dose, $6 \mathrm{~h}$ after the second dose, $6 \mathrm{~h}$ after the third dose, $6 \mathrm{~h}$ after the fifth dose, and on the seventh, ninth, and fifteenth day after injection.

All standards and samples were the processed and analyzed in the same manner. Briefly, perchloric acid (20 $\mu \mathrm{L}, 65 \%$ ) was added to the plasma-drug mixture, vortexed for $30 \mathrm{~s}$, and centrifuged for 5 min at $11.300 \times \mathrm{g}$. Supernatants were extracted and placed into new tubes. To each tube, $50 \mu \mathrm{L}$ of $2 \mathrm{M}$ dipotassium hydrogen phosphate was added; tubes were then mixed and centrifuged at $11.300 \times g$ for $1 \mathrm{~min}$. The resulting supernatants were supplied with $200 \mu \mathrm{L}$ sulfamerazine and injected into the HPLC system (Shimadzu, Tokyo, Japan) under the same conditions used for in vitro dissolution. The standard curve and standard equation were derived using Microsoft Excel (Amini and Ahmadiani, 2007).

\subsection{Data analysis}

Parasitemia, pharmacokinetics, as well as liver and kidney enzyme data were expressed as means \pm standard error of the mean (SEM). Life span was calculated as a percentage of the mean. All data was tested for Gaussian distribution using the D'Agostino-Pearson omnibus noramlity test and Shapiro-Wailk normality test. Experiments were designed with no matching or pairing. One-way analysis of variance (ANOVA) and Tukey's multiple comparisons test was used to anlayze the data for significance. P-value $<0.05$ were considered statistically significant.

\section{Declarations}

\section{Ethics approval}

All experiments were approved by the Unit of Biomedical Ethics Research Committee, King Abdulaziz University (Reference No 168-15; may 24, 2015).

\section{Consent to participate}

Not applicable.

\section{Consent for publication}

Not applicable.

\section{Availability of data and materials}


All data related to the current study are available from the author upon reasonable request.

\section{Competing interests}

The author declares that there is no significant competing professional, financial, or personal interests that may influence the performance or presentation of the current study.

\section{Funding}

This study was funded by King Abdulaziz University.

\section{Authors' contributions}

Z. N. designed and conducted the experiments and drafted the article for final submission.

\section{References}

1. Amini $\mathrm{H}$, Ahmadiani A. Rapid and simultaneous determination of sulfamethoxazole and trimethoprim in human plasma by high-performance liquid chromatography. J Pharm Biomed Anal. 2007;43:1146-50.

2. Craig MH, Kleinschmidt I, Nawn JB, Le Sueur D, Sharp BL. Exploring 30 years of malaria case data in KwaZulu-Natal, South Africa: Part I. The impact of climatic factors. Trop Med Int Health. 2004;9:1247-57.

3. Dawrea S, Pathak S, Sharma S, Devarajan PV. Enhanced antimalalarial activity of a prolonged release in situ gel of arteether-lumefantrine in a murine model. Eur J Pharm Biopharm. 2018;123:95-107.

4. El Shishtawy M, Hassan K, Ramzy R, Berri F, Mortada M, Nasreddine S, Ezzedine M. Comparative Toxicity Study of Chloroquine and Hydroxychloroquine on Adult Albino Rats. Eur Sci J. 2015;1.

5. Fontaine RE, Najjar AE, Prince JS. The 1958 Malaria Epidemic in Ethiopia. Am J Trop Med Hyg. 1961;10:795-803.

6. Jelinek T, Schulte C, Behrens R, Grobusch MP, Coulaud JP, Bisoffi Z, et al. Imported Falciparum malaria in Europe: sentinel surveillance data from the European network on surveillance of imported infectious diseases. Clin Infect Dis. 2002;34:572-6.

7. Jimmy E, Usoh I, Ekpo A, Umoh I. Serum liver enzymes as markers in assessing physiological tolerance of amalar, cotexin, chloroquine, and fansidar. EJBMSR. 2013;1.

8. Karunajeewa HA, llett KF, Mueller I, Siba P, Law I, Page-Sharp M, et al. Pharmacokinetics and efficacy of piperaquine and chloroquine in melanesian children with uncomplicated malaria. Antimicrob Agents Chemother. 2008;52:237-43.

9. Kofoed K, Petersen E. The efficacy of chemotherapy against malaria with chloroquine plus propguanil, mefloquine, and tovaquone plus propguanil in travelers from Denmark. J Travel Med. 2006;10:150-4.

10. Mahajan HS, Shah SK, Surana SJ. Nasal in situ gel containing a hydroxy propyl $\beta$-cyclodextrin inclusion complex of artemether: development and in vitro evaluation. J Incl Phenom Macrocycl Chem. 2011;70:49-58. 
11. Naing PA, Maung TM, Tripathy JP, Oo T, Wai KT, Thi A. Awareness of malaria and treatment-seeking behavior among persons with acute undifferentiated fever in the endemic regions of Myanmar. Trop Med Health. 2017;45:31.

12. Shankar AH. Nutritional modulation of malaria morbidity and mortality. J Infect Dis. 2000;182:S37-53.

13. Spira AM. Assessment of travellers who return home ill. Lancet, 2003;361:1459-69.

14. Van Eijk AM, Ayisi JG, Ter Kuile FO, Otieno JA, Misore AO, Odondi JO, et al. Effectiveness of intermittent preventive treatment with sulfadoxine-pyrimethamine for control of malaria in pregnancy in western Kenya: a hospital-based study. Trop Med Int Health. 2004;9:351-60.

15. Who WTO. World tourism barometer, 2004;2:22.

16. Yu T, Jagdish S. Controlled delivery of aspirin: effect of aspirin on polymer degradation and in vitro release from PLGA-based phase sensitive system. Int J Pharm. 2008;357:119-25.

17. Zelai NT. Novel approaches to the treatment of the rodent malaria parasite Plasmodium berghei in vivo. Thesis submitted to the university of Leicester. 2017

18. Zelai NT. A single dose of in situ gel formulation of the antimalarial drug chloroquine phosphate as a sustained prophylactic candidate for COVID-19. J Adv Pharm Technol Res. accepted.

\section{Figures}
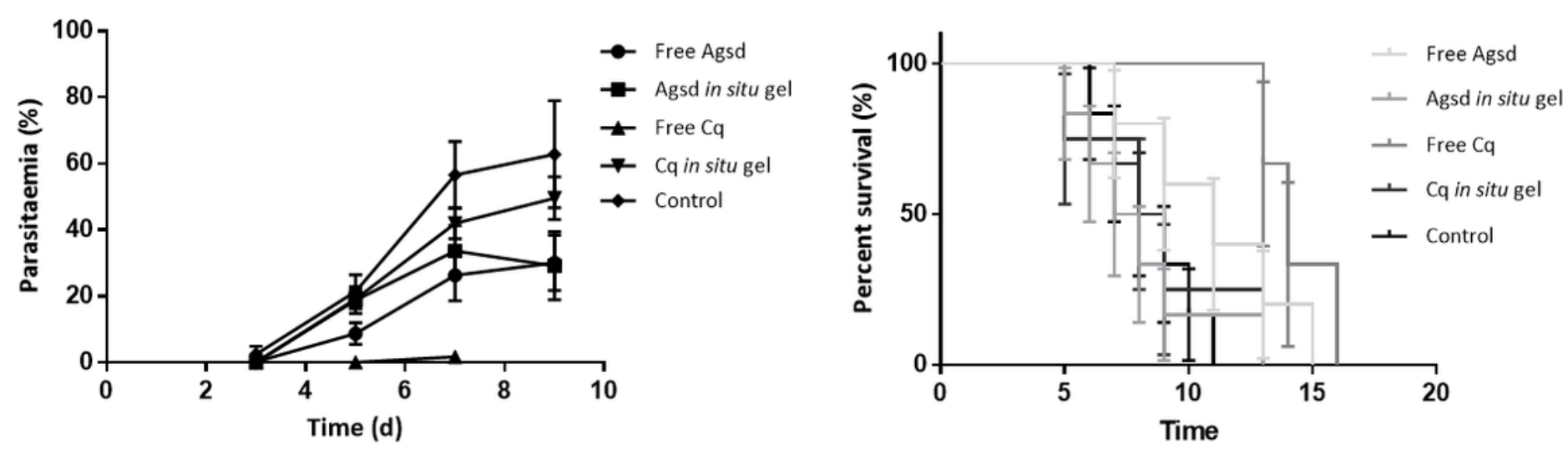

Figure 1

(A) Percentage of blood parasitaemia in the various mouse study groups ( $n=15$ per group). (B) Life span of the infected mice. Mice were treated with free or in-situ gel formulations of chloroquine and silver sulfadiazine four days before they were infected with Plasmodium berghe. The results of parasitaemia counting, showed that free $\mathrm{Cq}$ groups had a significantly less blood parasitaemia than others $(p=0.0408)$. Silver sulphadiazine (AgSd); Chloroquine (Cq). 

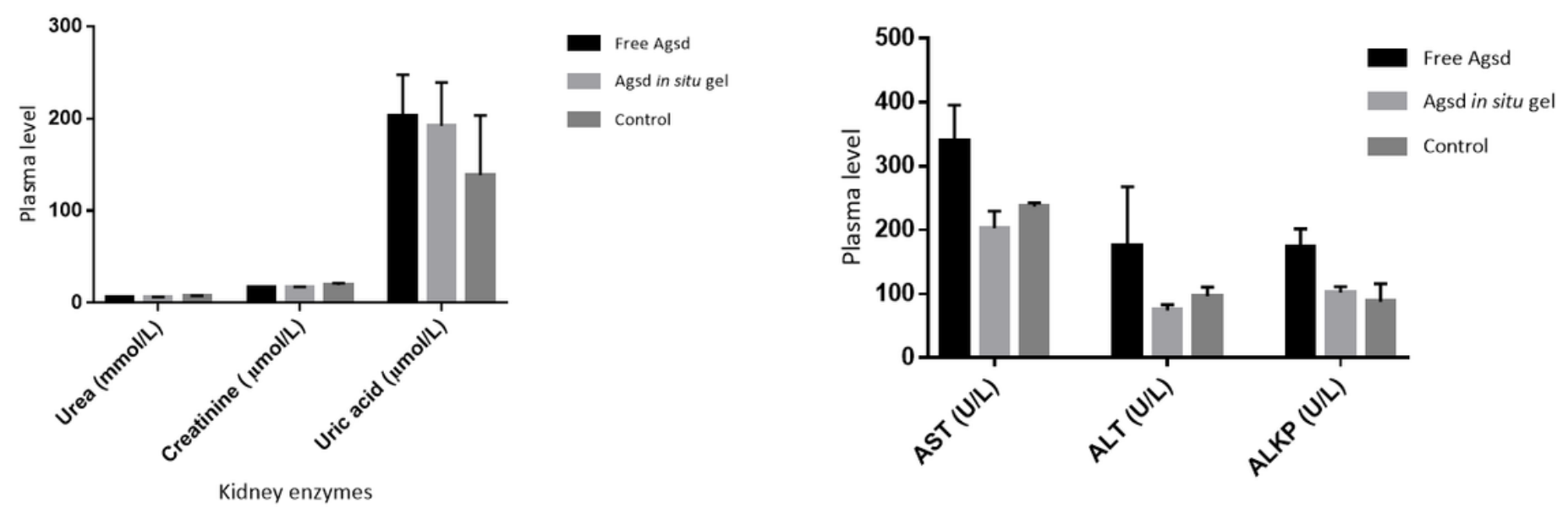

Liver enzymes

\section{Figure 2}

Changes in kidney and liver enzymes following treatment with different malaria prophylaxis drug formulations.

(A) Serum kidney enzyme (urea, creatine, and uric acid) levels within mice treated with free or in-situ gel Agsd.

(B) Serum liver enzyme (AST, ALT, ALKP) levels within mice treated with free or in-situ gel Agsd. All plasma enzymes levels were measured using Vitros 350. ( $n=3$ per group). Silver sulphadiazine (Agsd); Chloroquine $(\mathrm{Cq})$; aspartate aminotransferase (AST), alanine aminotransferase (ALT), and alkaline phosphatase (ALP).
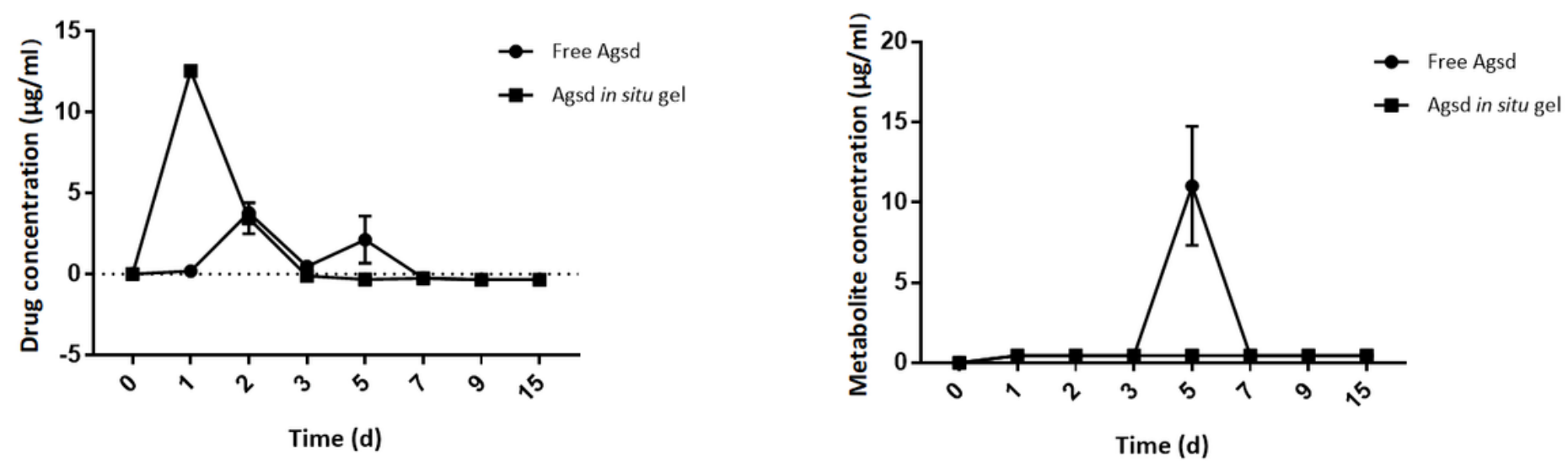

Figure 3

Pharmacokinetics of free and in-situ gelled Agsd formulations in blood plasma of treated mice. The levels of silver sulfadiazine $(A)$ and its main active metabolites $(B)$ were tracked in plasma over time using HPLC. ( $n=3$ per group). Silver sulphadiazine (Agsd). 